GRUPO EDUCACIONAL FAVENI

https://doi.org/10.47820/recima21.v3i2.1152

CAROLINA DE ARSOLINO ALMEIDA

ESTRATÉGIAS PARA O ENSINO DO CORPO HUMANO

SÃO GONÇALO - RJ

2019 


\section{CAROLINA DE ARSOLINO ALMEIDA}

GRUPO EDUCACIONAL FAVENI

\section{ESTRATÉGIAS PARA O ENSINO DO CORPO HUMANO}

Trabalho de conclusão de curso apresentado como requisito parcial à obtenção do título especialista em Ensino de Biologia.

Orientadora: Ana Paula Rodrigues.

SÃO GONÇALO - RJ 


\title{
ESTRATÉGIAS PARA O ENSINO DO CORPO HUMANO
}

Carolina de Arsolino Almeida ${ }^{1}$

Declaro que sou Carolina de Arsolino Almeida deste Trabalho de Conclusão de Curso. Declaro também que o mesmo foi por mim elaborado e integralmente redigido, não tendo sido copiado ou extraído, seja parcial ou integralmente, de forma ilícita de nenhuma fonte além daquelas públicas consultadas e corretamente referenciadas ao longo do trabalho ou daquelas cujos dados resultaram de investigações empíricas por mim realizadas para fins de produção deste trabalho.

Assim, declaro, demonstrando minha plena consciência dos seus efeitos civis, penais e administrativos, e assumindo total responsabilidade caso se configure o crime de plágio ou violação aos direitos autorais. (Consulte a 3ạ Cláusula, § 4ํㅡ, do Contrato de Prestação de Serviços).

\section{RESUMO}

O ensino atual carece de inovações pedagógicas que atendam as dificuldades existentes no processo de ensino aprendizagem dos alunos em salas de aulas. Pensando nisso, se procurou responder à questão? Como se fazer um eficaz ensino do corpo humano? Partiu-se da hipótese que novas estratégias pedagógicas são necessárias. Assim, o presente estudo tem como objetivo geral avaliar o ensino do corpo humano e as estratégias educacionais perante o processo de ensino aprendizagem. Este estudo será concebido através de uma pesquisa bibliográfica em diversas publicações e documentos legais que abordem a temática em questão.

PALAVRAS-CHAVE: Estratégias. Ensino. Ciências. Corpo. Humano.

\begin{abstract}
Current teaching lacks pedagogical innovations that address the difficulties in the process of teaching students' learning in classrooms. Thinking about it, did you try to answer the question? How to make an effective teaching of the human body? It was hypothesized that new pedagogical strategies are necessary. Thus, the present study has as general objective to evaluate the teaching of the human body and the educational strategies before the process of teaching learning. This study will be designed through a bibliographical research in several publications and legal documents that approach the subject in question.
\end{abstract}

KEYWORDS: Strategies. Teaching. Sciences. Body. Human.

\section{1- INTRODUÇÃO}

O presente estudo tem como objetivo geral avaliar o ensino do corpo humano e as estratégias educacionais perante o processo de ensino aprendizagem. Para isso, se fez como objetivos específicos desta pesquisa: Conceituar e compreender o processo de ensino aprendizagem. Estudar acerca do ensino do corpo humano e o uso de estratégias pedagógicas conforme o processo de ensino aprendizagem. Avaliar a importância do PIBID no ensino de ciências e o corpo humano. 
Este estudo será concebido através de uma pesquisa bibliográfica em diversas publicações e documentos legais que abordem a temática em questão. Este tipo de pesquisa é realizado a partir do levantamento de referências teóricas já analisadas, e publicadas por meios escritos e eletrônicos, como livros, artigos científicos, páginas de web sites. Importante esclarecer que qualquer trabalho científico inicia-se com uma pesquisa bibliográfica, que permite ao pesquisador conhecer o que já se estudou sobre o assunto. Existem, porém pesquisas científicas que se baseiam unicamente na pesquisa bibliográfica, procurando referências teóricas publicadas com o objetivo de recolher informações ou conhecimentos prévios sobre o problema a respeito do qual se procura a resposta (FONSECA, 2002), como foi o caso deste estudo.

Cumpre mencionar ainda que no percurso de desenvolvimento serão seguidas algumas etapas: a) identificação e delimitação do assunto, onde formulou-se um título para o levantamento bibliográfico e identificou-se os termos que expressassem os seus conteúdos.

b) identificação das fontes disponíveis, onde ocorrerá a escolha das fontes mais adequadas à pesquisa.

c) leitura, sendo que nesta fase serão descartados os trabalhos não relevantes, realizadas anotações temáticas em fichas.

e) redação, onde se realizará a escrita do trabalho propriamente dito.

\section{2 - O PROCESSO DE ENSINO APRENDIZAGEM}

$\mathrm{Na}$ pedagogia, vemos que diversas foram as posturas quanto ao processo de ensino e aprendizagem e sua relação com os aspectos afeto-cognitivos. Na educação tradicional, ao professor não interessa a experiência de vida do aluno, o seu estado emocional, pois o objetivo primeiro e último é a transmissão de conteúdo.

Entretanto no decorrer dos anos e com necessidade de atender as necessidades dos educandos, surgiram, pedagogos que tentam mudar esse modo de ver a educação e trazem contribuições de outra ordem, entre elas o estabelecimento, no cotidiano escolar, da emoção que o educando sentia, de sua experiência de vida, do seu estado emocional, do vínculo entre afeto e cognição. Entre outros, podemos utilizar para maior reflexão sobre a valorização do aspecto afetivo das condutas Comenius, Makarenko, Herbat, Dewey, os quais durante a trajetória pela universidade se destacaram na pedagogia e estudados mais profundamente revelam em sua proposta a relação entre afeto e cognição.

Freire destaca:

Por que não estabelecer umas necessárias 'intimidade' entre os saberes curriculares fundamentais aos alunos e a experiência social que eles têm como indivíduos? Por 
que não discutir as questões políticas e ideológicas de tal descaso dos dominantes pelas áreas pobres da cidade? (FREIRE, 1997, p. 33-34).

Segundo Freire (2008), podemos observar que o sentido do querer bem não é obrigatoriamente o sentido de querer bem a todos os alunos de forma idêntica. Possui o real significado de que a afetividade não é assustadora, mostrando como falsa a separação radical entre a seriedade docente e afetividade. O autor continua o raciocínio afirmando que, "não é certo, sobretudo do ponto de vista democrático, que o professor será tão melhor quanto mais severo, mais distante e “cinzento”, colocando-se nas relações com os alunos, no trato dos objetos cognoscíveis que deva ensinar" (FREIRE, 1997, p. 35)

Piaget dá ênfase no interacionismo, mostrando o papel ativo do sujeito, direcionando o seu foco para como a pessoa descobre o mundo, como ela se apropria dos conhecimentos e como ela interage com eles. Esse teórico acredita que o prático e lúdico são essenciais na vida da criança, constituindo-se em expressão e condição para o desenvolvimento, já que a criança assimila e pode transformar a realidade.

Os conceitos de acomodação e assimilação aparecem em todas as fases do desenvolvimento:

I - Acomodação: processo pelo qual o indivíduo modifica seu estágio mental em resposta a demandas externas.

II - Assimilação: processo pelo qual o indivíduo incorpora elementos do mundo externo ao seu próprio esquema.

O indivíduo, neste sentido, se apresenta como um ser dinâmico, que em todos os momentos faz interações com a realidade, podendo operar de forma ativa com as pessoas e os objetos. Sendo assim, a dinâmica de grupos também é extremamente relevante para a teoria de Piaget, isso porque fomenta a operação da inteligência em situação cooperativa, eliminando a pessoa de seu egocentrismo. Um diferente autor que se refere sobre o assunto é Lev S. Vygotsky, também enfatizando a visão interacionista, estando focado na função do meio e se preocupando com as interações sociais. Um procedimento pedagógico que é mediado, que privilegie o compartilhar de experiências e a valorização do conhecimento prévio, pode possibilitar a construção de novas relações, ampliando o conhecimento dos sujeitos envolvidos nesse processo. O sujeito passa a exercer um papel ativo, dialogando, interagindo, elaborando hipóteses e criando soluções para problemas, desenvolvendo, assim, certas capacidades de questionar, refletir e argumentar.

Segundo a concepção de Piaget, a atividade experimental corretamente elaborada é a prática pedagógica de maior relevância. 
Ainda se fundamentando nos trabalhos de Piaget (1973 apud FREIRE, 1997), ainda as sensações físicas mais comuns pressupõem um quadro interno de interpretação. Significando assim que uma operação lógico-matemática faça intervenção em qualquer sensação, no tocante da informação apreendida pelo sujeito. Desta forma, mesmo que partir da sensação, o conhecimento se liberta desta pelo processo de reelaboração (interna do próprio sujeito). Qualquer conhecimento constitui-se, portanto, da reinterpretação de uma operação elementar (dado físico ou primário), segundo as estruturas cognitivas do sujeito, num processo de reelaboração (FREIRE, 2008).

Nesse contexto podemos recorrer novamente a Vygotsky (2007), que compreende os afetos em duas classes, positivos e negativos. Os afetos positivos estão relacionados a emoções positivas de alta energia, como o entusiasmo e a excitação, e de baixa energia, como a calma e a tranquilidade.

Os afetos negativos, por sua vez, estão ligados às emoções negativas, como a ansiedade, a raiva, a culpa e a tristeza.

A relação mãe-bebê, por exemplo, é uma relação extremamente importante porque é a mãe quem cria as primeiras situações emocionais que influenciarão o desenvolvimento da criança $^{1}$. Na perspectiva sociocultural de Vygotsky (2007), a afetividade é um elemento cultural que faz com que tenha peculiaridades de acordo com cada cultura. Elemento importante em todas as etapas da vida das pessoas, a afetividade tem relevância fundamental no processo ensino-aprendizagem no que diz respeito à motivação, avaliação e relação professor-aluno.

Entender os princípios do processo de aprendizagem é primordial para educadores e pais, pois a partir desta compreensão, os problemas que ocorrem nesta área serão tratados e resolvidos sem traumas ou bloqueios. Vale então ressaltar os conceitos de aprendizagem segundo alguns autores, apresentados no decorrer deste capítulo. Contudo, para iniciar o conceito de aprendizagem é importante elucidar que a aprendizagem é uma mudança de probabilidade da resposta, devendo especificar as condições sob as quais ela acontece.

Destarte, o fundamento de sua teoria se estabelece prevendo o papel da recompensa ou do reforço ${ }^{2}$, partindo do enunciado que toda a ação que venha a produzir determinada satisfação possui a disposição em ser repetida e dessa forma, aprendida. Assim, há um condicionamento

\footnotetext{
${ }^{1}$ Uma característica comum nas teorias de desenvolvimento afetivo de Piaget, Wallon e Vygotsky são o consenso quanto aos aspectos cognitivo-afetivos do desenvolvimento e da aprendizagem.

${ }^{2}$ SKINNER entende as diferenças entre o reforço positivo e o reforço negativo como planos de modificação do comportamento. Em ambos os casos, ocorre a transformação comportamental. Para o reforça mento positivo há uma recompensa na resposta dada a um comportamento desejado; o reforço negativo acontece quando alguma ação passa a evitar uma consequência indesejada. Para SKINNER "no condicionamento operante, um mecanismo é fortalecido no sentido de tornar uma resposta mais provável, ou melhor, mais frequente ", (SKINNER, 2007, p. 46) podendo ser utilizado em sala de aula pelo professor como uma estratégia de ensino e de retenção do conhecimento pelos seus estudantes.
} 
do indivíduo cognitivo que buscará uma resposta que o beneficie, em virtude de um comportamento considerado prudente e que seja avaliado como um estímulo positivo.

Nesse sentido, o comportamento humano passa a ser controlado por uma padronização de estimulo e resposta, em uma iminente probabilidade de repetição de atos e ideias. Esse fundamento é considerado pelo behaviorismo, estudado por Leonard BLOOMFIELD e explicado por SKINNER como "um processo de estratégia de ensino", considerando fundamentos materializados previamente em condicionantes do comportamento. Nesse interim, "todo organismo vivo quando estimulado inicia uma resposta".

Entretanto, ao considerar o reforço que decorre de uma resposta influenciada por um estimulo positivo, dependerá de fatores diversos no processo de aprendizagem, que podem ser utilizados em ambientes que propiciem ao estudante compreender e executar os comportamentos que se pretende estimular.

Paulo Freire (2008) também fala da importância da participação livre e ativa dos educandos, juntamente com o professor, na construção coletiva dos saberes, havendo assim uma troca de conhecimentos muito enriquecedora no processo de ensinoaprendizagem. Nesta linha de pensamento de Paulo Freire, podemos compreender que a escola tem um dever essencial: a formação de todos os homens de forma crítica, ou seja, a criação do cidadão que detêm conhecimento de seus direitos e de suas responsabilidades.

VIGOTSKY afirma que a aprendizagem promove desenvolvimento através do relacionamento com as pessoas, confirmando a necessidade da interação com o outro para a identificação do eu subjetivo.

VIGOTSKY acreditava que aprendizagem ocorre durante toda a vida do indivíduo, ou seja, entende que o processo de:

Formalização do conhecimento proposto pela escola não é a única fonte que o sujeito possui para aprender", ao ser reconhecido e perceber a si mesmo nas interações humanas ao redor em ambientes sociais, podendo atribuir a seu conhecimento qualquer valor, pois "isso está inato às capacidades humanas, conseguindo assim, aprender com qualquer situação vivida. (VYGOTSKY, 2007).

Sobre o processo de aprendizagem, VIGOTSKY considera que somente no encontro com o outro o homem passou a ser perceber como um ser racional, quando a constituição do indivíduo unicamente é possível através de uma "mediação realizada através do outro" (VIGOTSKY, 2007, p. 57).

Apesar do processo de ensino - aprendizagem da criança não iniciar no ambiente escolar, é de extrema relevância que esta frequente a escola, pois este espaço introduz novos elementos em seu desenvolvimento, apresentando o outro. De acordo com a ideologia de VIGOSTKY, aprendizagem e desenvolvimento estão inter-relacionados desde o primeiro dia de vida da 
criança. Foi com base nesta ideia que o autor desenvolveu o conceito de Zona de Desenvolvimento Proximal e Zona de Desenvolvimento Real, ensinando que o “desenvolvimento real é a parte que se refere ao desenvolvimento retrospectivo, enquanto a zona de desenvolvimento proximal aponta para o desenvolvimento mental perspectivo" (VIGOTSKY, 2007).

Para entender estes conceitos pode-se considerar o pensamento de OLIVEIRA (1995, p.60) ao explicar essa teoria. Segundo ele, a zona de desenvolvimento proximal refere-se ao caminho que o indivíduo vai percorrer para desenvolver funções que estão em processo de amadurecimento, e que se tornarão funções consolidadas, estabelecidas no seu nível de desenvolvimento real. A zona de desenvolvimento proximal é, pois, um domínio psicológico em constante transformação; aquilo que uma criança é capaz de fazer com a ajuda de alguém hoje, ela conseguirá fazer sozinha amanhã. É como se o processo de desenvolvimento progredisse mais lentamente que o processo de aprendizado; o aprendizado desperta o processo de desenvolvimento que aos poucos, vão tornando-se parte das funções psicológicas consolidadas do indivíduo.

É importante destacar que somente mediante os processos de aprendizagem há a possibilidade de incorporarem-se novos conhecimentos, valores e habilidades que são próprios da cultura e da sociedade em que se vive. Nesse sentido, a interpretação individual das pequenas relações sociais no ambiente da sala de aula produz a interação e assim, a construção humana em seus aspectos modelares da identidade.

Todas essas teorias (comportamentalista, fenomenológica e psicanalista) acabam privilegiando o enfoque de que as ocasiões objetivas ou subjetivas fazem a determinação do homem, traduzindo uma interpretação naturalizada, positiva do ambiente ou da natureza humana. Desta forma, os estudos de Piaget, Wallon e Vygotsky acabam superando as teorias comportamentalistas, fenomenológicas e psicanalistas, propondo então um tipo de abordagem interacionista, situação onde o sujeito e o objeto, interagem, sugerindo assim que, o sujeitoobjeto, não somente são influenciados pela ação do meio e da subjetividade, mas sim tende a esclarecer que o subjetivo e o objeto vivenciam as alterações a partir da relação que são estabelecidas entre eles.

\section{3 - O ENSINO DO CORPO HUMANO}

Devemos ressaltar que o ensino do corpo humano é extremamente relevante para a adequada formação do aluno, levando em consideração que é importância ter um adequado conhecimento e compreensão da complexidade do seu próprio organismo, dinâmico, voluntário e involuntário com a capacidade de gerar novas vidas e de fazer coisas mais interessantes. 
Entretanto, infelizmente o referido tipo de ensino está sendo pouco eficiente durante seu dia a dia na sala de aula, passando a ser algo de pouco valor. O referido tipo de problema resulta-se da junção de diferentes fatores, onde são ignorados em diversas ocasiões.

Ademais, os livros didáticos tratam incessantemente o corpo humano como sendo uma junção das partes, fazendo com que o aluno não compreenda adequadamente o fato de ser um único organismo, contando com variadas reações químicas e atividades que ocorrem ao mesmo tempo. Os dizeres dos PCN dizem assim sobre o tema:

Para que o aluno compreenda a integridade do corpo, é importante estabelecer relações entre os vários processos vitais, e destes com o ambiente, a cultura ou a sociedade. São essas relações que estão expressas na arquitetura do corpo e faz dele uma totalidade. Discernir as partes do organismo humano é muitas vezes necessário para entender suas particularidades, mas sua abordagem isolada não é suficiente para a compreensão da ideia do corpo como um sistema. Portanto, ao se enfocar anatomia e fisiologia humanas é necessário selecionar conteúdos que possibilitem ao estudante compreender o corpo como um todo integrado, não como somatório de partes (BRASIL, 1998, p. 45).

Cabe observar ainda que a concepção de corpo humano é feita de forma pessoal, sendo a consequência de influências do contexto histórico, onde o aluno se encontra inserido. Dessa maneira, é possível encontrar diferentes concepções que não podem ser abalizadas como certas ou erradas sem que possam ser discutidas na instituição de ensino. No decorrer da história humana, já foram e ainda são elaboradas várias concepções de corpo e de comportamento corporal, podendo ser submetidas aos valores sociais e sentimentais. Neste sentido, a concepção de corpo tende a ser então individual e não geral.

Vejamos:

O conhecimento sobre o corpo humano para o aluno deve estar associado a um melhor conhecimento do seu próprio corpo, com o qual tem uma intimidade e uma percepção subjetiva que ninguém mais pode ter, já que cada corpo é individual, único (BRASIL, 1998; p. 46).

As palavras de Cicillini \& Santos (2002) apontam que na atualidade, o ensino de ciências nas instituições de ensino:

É norteado pelo método tradicional de ensino, sendo baseado pela transmissão de conteúdos pelo professor, e recepção dessas informações pelo aluno. Tal método não leva em consideração os conhecimentos prévios dos alunos, suas experiências e condições mentais para aprendizagem, sendo exigido deste apenas a reprodução fiel de tais informações segundo esperado pelo professor. Com isso o conhecimento não se efetiva na sala de aula, ocorrendo apenas meras trocas de informações privando o aluno de participar de seu próprio processo de aprendizagem. (CICILLINI e SANTOS, 2002, p. 35). 
Entretanto, o ensino relacionado ao corpo humano englobado pela disciplina de ciências precisa ser colocado em prática de maneira que o estudante seja capaz de ter novos pensamentos sobre este conhecimento, de maneira contextualizada, em outras palavras, leve o ensino para a sua realidade.

Segundo a concepção de Rabello (1994), que leciona dizendo assim sobre o assunto:

O estudo do corpo humano instiga os estudantes, estimula-as a questionar e voltar seu olhar para seu próprio corpo, já que estão em fase de constantes mudanças. Cabe ao professor aproveitar tais momentos para perceber qual a noção de corpo humano que seus alunos possuem e a partir desta informação direcionar seu ensino para que possa atender aos questionamentos de seus alunos (RABELLO, 1994, p. p. 74).

É preciso ressaltar ainda que:

O estudo do corpo humano é envolvido por uma abordagem logicista que corresponde a um percurso no qual se parte do mais simples e chega-se ao mais complexo, importando a lógica do conteúdo e não a do aluno. Esta perspectiva de ensino, possivelmente, está fundamentada na representação social do professor uma vez que, nesta há uma ênfase sobre a dimensão física de corpo humano (SHIMAMOTO, 2004, p. 8).

Dessa maneira, é preciso que se estimule o aluno a fazer questionamentos referentes à fisiologia e/ou anatomia humana, a fim de buscar por respostas que solucionem essas questões, possibilitando que os mesmos possam ter maiores noções sobre o seu corpo, como sendo um todo integrado e poder articular adequadamente a sua vida com o ambiente físico e social onde está inserido.

Sendo muito relevante, então, adquirir adequadamente os conhecimentos referentes ao corpo humano que se associam diretamente com as noções de saúde e com os conteúdos associados ao autocuidado do indivíduo. Sendo possível mencionar, para exemplificar, os conhecimentos que possibilitam os alunos a analisarem os seus órgãos dos sentidos, as estruturas que se responsabilizam pelos órgãos mais variados das sensações, fazer então a junção da sua prática de higiene com os cuidados básicos, objetivando assim conservar um correto funcionamento dos referidos órgãos e do seu autoconhecimento.

Ficando assim evidente que há alguns empecilhos ao se lecionar ciências, por conta da utilização dos termos técnicos. Entretanto, é preciso que se tenha o adequado domínio da referida linguagem científica, situação em que qualquer tema de ciências necessite de conhecimentos minuciosos sobre as nomenclaturas corretas. Mas, assim como leciona Luvizoto (2011, p. 48), podemos ver que nos casos de uma "metodologia que defende o estudo visando à cultura científica, o ideal é auxiliar a construção de conhecimentos que favoreçam a 
compreensão daquilo que ele vivencia e não saber de cor o número de ossos ou os nomes deles".

Segundo os estudos de Malafaia e Rodrigues (2011), podemos ver que ao passo em que são elaboradas e praticadas novas estratégias educacionais, considerando sempre as peculiaridades dos alunos, esse processo de ensino-aprendizagem passa a ser cada dia mais eficaz e prazeroso para o estudante.

\section{4 - PIBID NO ENSINO DE CIÊNCIAS E O CORPO HUMANO}

Podemos ver que Programa de Iniciação à Docência - PIBID auxilia relevantemente para a maximização da qualidade do processo de ensino e aprendizagem, isso por meio da melhor qualificação profissional ao se formar os futuros docentes, introduzindo também os profissionais no dia a dia da instituição de ensino, fomentando assim uma maior aproximação da escola com as instituições de ensino superior e podendo proporcionar para os seus estudantes de licenciaturas a chance de atuar em experiências mais novas no decorrer da sua graduação (BRAIBANTE e WOLLMANN, 2012). Já os estudos de Silva et. al. (2012) apontam a grande relevância dessa oportunidade que o PIBID proporciona para os discentes, os futuros professores, que é a de ter maior conhecimento sobre todos os aspectos políticos e pedagógicos que devem englobar a dinâmica das atividades da instituição de ensino.

Dessa maneira, o ensino realizado através de investigação por meio da resolução de problemas que se fundamentam na teoria de John Dewey e Schwab (GIL-PÉREZ, 2000; ZÔMPERO et. al. 2013). Onde então o desenvolvimento das atividades deve acontecer a partir de um problema/problematização. Já segundo os estudos de Campos et. al. (2008) e Gil (1993), podemos ver que o ensino por investigação torna possível, além de uma aprendizagem conceitual, também uma aprendizagem de procedimentos e habilidades. Realizar então uma abordagem dos três momentos pedagógicos se fundamenta nas abordagens de Freire (1987), Delizoicov (2002) e Gehlen et. al. (2012), onde os autores ressaltam em uma problematização como intuito de potencializar o processo de ensino-aprendizagem.

Sendo assim, entre as inúmeras metodologias alternativas de ensino, podemos ressaltar os jogos, os modelos e a modelização, representações/desenhos esquemáticos e, dinâmicas, isso porque, mesmo todos esses contarem com relevantes e específicas peculiaridades, em um contexto geral, todos apresentam o mesmo objetivo final, que é fazer com o que o conhecimento seja mais acessível e importante para os alunos. Os estudos feitos por Franco e Carvalho (2012) e também as pesquisas de Nascimento et. al. (2015), onde os autores evidenciam que os modelos didáticos são semelhantes a um sistema figurativo que faz a reprodução da realidade de maneira especializada e concreta, transformando o ensino em algo mais fácil de compreender para o 
aluno, realizando assim uma aprendizagem de maior eficiência, levando em consideração que o estudante vivencia inúmeros tipos de desafios, tendo a capacidade de solucionar os problemas usando a sua criatividade e a sua imaginação.

\section{5 - CONCLUSÃO}

Deixando assim, muito clara a necessidade de se repensar em quais devem ser as mais adequadas práticas pedagógicas voltadas para a disciplina de ciências relacionada ao estudo do corpo humano, isso porque elas podem influenciar diretamente em uma diversidade de fatores que afetam as práxis educativas e se relacionam ainda com o processo de ensino-aprendizagem dos alunos.

Levando em consideração a demanda pela criação de novas abordagens e opções metodológicas alternativas da tradicional, podendo essas proporcionar uma maximização da eficácia da aprendizagem e do ensino de ciências e biologia, sendo então um processo de construção de conhecimento mais importante e relevante para a vida dos profissionais que estão envolvidos no referido processo, especialmente levando em consideração um mundo mais globalizado e de relevantes avanços científicos e tecnológicos que podem influenciar tanto no meio ambiente como também na saúde das pessoas.

Portanto, as afeições do professor influenciam a vontade de aprender dos alunos.

\section{6 - AGRADECIMENTOS}

À minha mãe Maria Christina, por sua capacidade de acreditar e investir em mim. Mãe, seu cuidado e dedicação foi o que me deu, em todos os momentos, a esperança pra seguir em frente e a minha Tia Lucília, que a sua presença significou segurança e certeza de que nunca estive sozinha nessa caminhada.

\section{7- REFERÊNCIAS}

BRASIL. Ministério da Educação. Secretaria de Educação Fundamental. Parâmetros curriculares nacionais: terceiro e quarto ciclos - Ciências Naturais. Brasília: MEC /SEF, 1998.

BRAIBANTE, M. E. F.; WOLMANN, E. M.A Influência do PIBID na Formação dos Acadêmicos de Química Licenciatura da UFSM. Química Nova na Escola. v. 34, n 4, p. 167 $172,2012$.

CARVALHO, A.M.P.; GIL-PÉREZ, D. Formação de professores de ciências. São Paulo: Cortez, 2000.

CAMPOS, L. M. L; BORTOLOTO, T.M.; FELICIO, A.K.C. A produção de jogos didáticos para o ensino de ciências e biologia: uma proposta para favorecer a aprendizagem. 2008. 
Disponível em: http://www.unesp.br/prograd/PDFNE2002/aproducaodejogos.pdf . Acesso em: Novembro de 2018.

DELIZOICOV, D. et al. Ensino de Ciências: fundamentos e métodos. São Paulo: Cortez, 2002.

FRANCO, O. M.; CARVALHO, S. C. R. Moléculas de H2O: desenvolvimentos de materiais didáticos para uma abordagem no ensino de ciências naturais, biologia e química. Revista Sapiência: sociedades, saberes e práticas educacionais. Iporá, v.1, n.1, p. 113-120, 2012.

FREIRE. P. Pedagogia do oprimido. 17. ed. Rio de Janeiro: Paz e Terra, 1987.

FREIRE, Paulo. Pedagogia da Autonomia: saberes necessários à prática educativa. São Paulo: Paz e Terra, (Coleção Leitura). 1997.

FREIRE, Paulo. A importância do ato de ler: em três artigos que se completam. $49^{\mathrm{a}}$ ed. São Paulo: Cortez, 2008.

FONSECA, J. J. S. Metodologia da pesquisa científica. Fortaleza: UEC, 2002.

GEHLEN, S. T; MALDANER, O. A; DELIZOICOV, D. Momentos pedagógicos e as etapas da situação de estudo: complementaridades e contribuições para a educação em ciências. Ciência \& Educação, v. 18, n. 1, p. 1-22, 2012.

GIL-PÉREZ, D. Contribuición de la historia y de la filosofia de las ciencias al desarrolo de um modelo de enseñanza/aprendizage como investigación. Enseñanza de las Ciencias, Barcelona, v.11, n. 2, p. 197-212, 1993.

LIMA, Ana Lúcia D Império; ROSENDO, Rosi. Séries finais do ensino fundamental: o pael das TICs na etapa mais desafiadora do ensino básico. In: ALMEIDA, Virgílio Augusto Fernandes et al. TIC Educação 2013: Pesquisa sobre o Uso das Tecnologias de Informação e Comunicação nas Escolas Brasileiras. São Paulo: Db Comunicação Ltda, 2013. Cap. 73. p. 73 80. Disponível em: http://www.cetic.br/media/docs/publicacoes/2/tic-educacao-2013.pdf . Acesso em: Novembro de 2018.

LUVIZOTO, C. Como ensinar sobre corpo humano? Revista Nova Escola, São Paulo, Nov. 2011.

MALAFAIA, G.; RODRIGUES A. S. de L USO DA TEORIA DAS INTELIGÊNCIAS MÚLTIPLAS NO ENSINO DE BIOLOGIA PARA ALUNOS DO ENSINO MÉDIO SaBios: Rev. Saúde e Biol., v.6, n.3, p.08-17, set./dez., 2011.

NASCIMENTO, F. et al. O ensino de ciências no Brasil: história, formação de professores e desafios atuais. Revista História, Sociedade e Educação no Brasil, 39, p. 225-249, 2010.

NASCIMENTO, L. C. S. et al. O uso de modelização como estratégia didática no ensino de platelmintos. Carpe Diem: Revista Cultural e Científica do UNIFACEX, v. 13, n. 1, p. 93 $106,2015$.

RABELLO, S. H. dos S. A Criança, Seu Corpo, Suas Ideias. Ensino Em-Revista, v.3, n.1, 1529, jan/dez.1994. Universidade Federal de Uberlândia, da Faculdade de Educação/EDUFU. 
SANTOS, K. A. dos. S; CICILlINI, G.A. Concepções de Professores sobre o Ensino de Ciências nas Séries Iniciais do Ensino Fundamental. Ensino Em Revista. Uberlândia, v.11, n.1, jul.2002/jun.2003. Universidade Federal de Uberlândia, da Faculdade de Educação/ EDUFU

SILVA, C. da S. et al. O Saber Experiencial na Formação Inicial de Professores a Partir das Atividades de Iniciação à Docência no Subprojeto de Química do PIBID da Unesp de Araraquara. Química Nova na Escola. v. 34, n 4, p. 189-200, 2012.

SHIMAMOTO, D. F. Representações sociais dos professores de ciências naturais sobre corpo humano. Tese (doutorado). Universidade Federal de São Carlos. São Paulo, 2004.

SKINNER, Burrrhus Frederic. Ciência e comportamento humano (J. C. Todorov \& R. Azzi, Trads.). São Paulo, SP: Martins Fontes, 2007.

VIGOTSKY, Lev Semenovitch. A formação social da mente. Martins Fontes, São Paulo, 2007.

ZÔMPERO, A. F et al. de Diferenciação e reconciliação de significados produzidos por alunos dos anos iniciais em atividades investigativas: uma abordagem ausubeliana. Experiências em Ensino de Ciências v.8, n. 2, p.116-126, 2013. 